\title{
Utilization of Flexible Demand in a Virtual Power Plant Set-Up
}

\author{
Thavlov, Anders; Bindner, Henrik W.
}

Published in:

IEEE Transactions on Smart Grid

Link to article, DOI:

10.1109/TSG.2014.2363498

Publication date:

2014

Link back to DTU Orbit

Citation (APA):

Thavlov, A., \& Bindner, H. W. (2014). Utilization of Flexible Demand in a Virtual Power Plant Set-Up. IEEE Transactions on Smart Grid. https://doi.org/10.1109/TSG.2014.2363498

\section{General rights}

Copyright and moral rights for the publications made accessible in the public portal are retained by the authors and/or other copyright owners and it is a condition of accessing publications that users recognise and abide by the legal requirements associated with these rights.

- Users may download and print one copy of any publication from the public portal for the purpose of private study or research.

- You may not further distribute the material or use it for any profit-making activity or commercial gain

- You may freely distribute the URL identifying the publication in the public portal

If you believe that this document breaches copyright please contact us providing details, and we will remove access to the work immediately and investigate your claim. 


\title{
Utilization of Flexible Demand in a Virtual Power Plant Set-Up
}

\author{
Anders Thavlov, Student Member, IEEE, and Henrik W. Bindner, Member, IEEE
}

\begin{abstract}
High penetration levels from renewable energy sources in large-scale power systems demand a high degree of flexibility in the transmission and distribution system. This paper presents a method for utilization of flexible demand in the low-voltage distribution system using the thermal mass of a building to defer power consumption from electric space heating. The power consumption for heating is controlled by an operational virtual power plant, which is sending a set point for requested power consumption to the building management system. An optimization problem is formulated such that the discrete dispatch of power from ten electric space heaters is following the power set point given constraints on the indoor comfort that is defined by the users of the building. The controlling method has been implemented in an intelligent office building and used for demonstration of flexible demand in the low voltage network.
\end{abstract}

Index Terms-Demand response (DR), demand-side management, flexible load, heat dynamics, smart grid, virtual power plant (VPP).

\section{INTRODUCTION}

$\mathbf{F}$ LEXIBLE demand for power is expected to play a key role in the future power system - or smart grid — and is by many seen as a prerequisite for integration of large amounts of renewable energy. The benefits of implementation of flexible power consumption are many; these include the possibility of shifting power consumption from peak load hours to periods with less demand, consequently reducing the need for spinning reserves. Furthermore, by a better coordination of the units connected in the low-voltage network congestion problems can be avoided, and hence flexible demand can help to reduce investments in the distribution grid.

Until recently, power consumers have been regarded as passive players in the power system and only the generation side has been involved in the process of controlling the system balance. Now, large industrial companies are being integrated as active players in the power system through the power market, trying to reduce cost of operation by running industrial processes during periods with inexpensive power. The variety of flexible processes is large and varies from pumping a fixed volume of water during a day to cold storages

Manuscript received September 20, 2013; revised January 8, 2014, April 26, 2014, and August 5, 2014; accepted October 9, 2014. This work was supported in part by DONG Energy and in part by the Danish Academy of Wind Energy. Paper no. TSG-00742-2013.

The authors are with the Department of Electrical Engineering, Technical University of Denmark, Rosiklide 4000, Denmark (e-mail: atha@elektro.dtu.dk).

Color versions of one or more of the figures in this paper are available online at http://ieeexplore.ieee.org.

Digital Object Identifier 10.1109/TSG.2014.2363498 which have to maintain a maximum temperature. There is, however, also a large potential in the integration of the numerous small entities connected in the low voltage grid. Two main approaches for control of demand-side resources (DSR) are currently being pursued; the first one is utilizing indirect control, where an incentive signal, possibly a price signal, is broadcast to a large number of DSRs to incentivize changes in power consumption. The second one is direct control, where a centralized controller-or coordinator-is directly controlling a number of distributed energy resources (DERs) by sending a reference set point for requested power consumption or generation to each of them. Moreover, there exist other approaches for control, for example autonomous and transactional control as defined in [1]. Whereas indirect control relies on a stochastic demand response (DR) from DSRs, direct control can deliver a requested DR with a high certainty relative to indirect control. This, however, comes at a higher investment cost, due to the need of establishing a dedicated communication link, possibly bidirectional, between the central controller and the DSR. When direct control is used to aggregate a number of units, the aggregator is typically called a virtual power plant (VPP). The reference to power plants refers to the high certainty of up- and down-regulation of the aggregator, due to the usage of direct control.

Several projects are investigating the benefits of integration of residential households as active players in the power system. In the Pacific Northwest GridWise Demonstration project, a $20 \%$ reduction in peak load was obtained by control of appliances in residential and commercial buildings using a broadcast electricity price signal [2]. A similar approach is used in the ongoing EcoGrid EU project, where flexible demand from 2000 residential customers, on the Danish island Bornholm, is used to balance power in a power system with $50 \%$ power generation from renewable energy sources [3]. In the cell controller pilot project, a direct control approach is used to coordinate the response from DER, e.g., CHP plants and wind turbines, to deliver power system services in the distribution system [4].

Research within DR has gained a lot of attention within the last decade; consequently, there exists many studies in building management systems (BMS) providing optimal control of commercial and residential appliances with respect different criteria. As outlined earlier, these can generally be separated into indirect and direct control; especially indirect control using economic model predictive control (EMPC) with respect to price signals has received a lot of attention. In [5], 
an autoregressive model with exogenous input (ARX) is used together with EMPC to determine an optimal space cooling schedule with respect to a given rate plan. Likewise, in [6] a nonconvex EMPC method is proposed to minimize cost of refrigeration in a nonlinear commercial refrigeration system using hourly spot prices from the Nordic power market. In [7], EMPC is used to optimize space heating from a heat pump, with respect to both cost of electricity as well as the load level of the distribution grid. Similarly, in [8] predictive control is used to comply with a contractual peak power constraint, which is typically imposed on private customer in France and Italy. Direct control has received less attention despite that DR using direct control has been implemented by several energy companies; for example by Southern California Edison, the primary electric company in California, which is enrolling their private customers in DR programs, by offering a discount on electricity if they allow the utility to switch off their central air conditioning $(\mathrm{A} / \mathrm{C})$ unit during peak load hours. This paper presents a novel approach for delivering DR from an intelligent office building, using a VPP set-up. Due to the server/client relationship between the VPP and the controlled DSR, EMPC is implicitly carried out by the VPP. Hence, EMPC is not an option on the client side; instead, a dispatch problem is formulated, which optimizes the discrete power consumption from a number of resistance heaters-or Ohmic heaters-with respect to a set point for power consumption provided by the VPP.

This paper is organized as follows; initially, in Section II, a description of the VPP, Power Hub [9], and the interface to the VPP is given. Next, a model for heat load predictions is derived, and an optimization problem for the control of electric space heating in a building is formulated. In Section III, results from a series of experiments using an intelligent office building as a flexible load, are presented. Finally, in Section IV, the results are discussed and the conclusion is given.

\section{Methodology}

In this section, we present the VPP set-up and the theory for implementation of flexible heat consumption in an intelligent building that is heated by electric resistive heaters.

\section{A. Power Hub}

Power Hub is an implementation of a VPP that is currently being tested under market conditions in the Nordic power market. Power Hub has been developed by the Danish energy company DONG Energy as part of the Twenties project [10], which is supported by the European Commission. The main objective of the Twenties project is to investigate how large amounts of wind energy can be integrated into large-scale power systems. The main purpose of Power Hub is to increase the flexibility in the power system by allowing small power consuming and generating units to participate actively in the power market, thus contributing as a balance to the intermittent generation from the renewable energy sources.

By aggregation of small units, i.e., units with rated power generation or consumption of less than $1 \mathrm{MW}$, Power Hub is able to coordinate the response of numerous of units thus increasing the total effect of DR. Additionally, Power Hub lets small generation and consumption units, that are otherwise too small, to participate in the power market. A large-scale demonstration of Power Hub was carried out on the Faroe Islands in November 2012, where load shedding from three industrial companies were actuated to prevent a total island blackout due to a simulated $10 \%$ power loss in the total national supply.

In operation, Power Hub manages a portfolio of consumption and generation units, which in the following are named local units (LUs). During the day, Power Hub minimizes the cost of operation for consuming LUs, by shifting power consumption to periods with less expensive power. Likewise, the output of power generating LUs are increased-or activatedwhen the price is relatively high, thus increasing the income for the LU owner. Each unit is controlled locally given a set point for a requested consumption or generation, which is provided centrally from Power Hub. To ease integration of new units a standardized interface has been developed, which is available on the site of the LU through a remote terminal unit (RTU).

To plan the day of operation, a daily load or generation forecast is generated for each LU by their respective owner. These forecasts have to be received by Power Hub no later than 10 A.M. the day before operation, such that potential flexibility can be bid into the day-ahead market in the Nordic power market, Elspot. Bids into the day-ahead market have to be received by Elspot before gate-closure at noon, the day before operation. Flexibility that is not bid into the day-ahead market, or did not receiving any contract therein, can be saved for primary reserve, which can be activated on request from the transmission system operator. During the day of operation Power Hub can request changes to the power generation or consumption of an LU if imbalances in the power system emerge or if regulation power is needed. This is achieved by sending an updated power set point of the requested generation or consumption to an LU through the RTU. Within some predefined constraints, defined by the LU owners themselves, an LU is expected to comply with changes in power set point.

In the following, the heat consumption of an office building is being modeled and controlled by Power Hub; other parts of power consumption, which are mainly inflexible, are not considered in this paper since they cannot be postponed or accelerated. The controller can be seen as having influence on the fuse block which contains the electric heating only.

\section{B. Power Hub Interface}

On the LU-or client-side, the interface is represented physically by an RTU, which is communicating with Power Hub over a GPRS connection. The connection is facilitated by the IEC 60870-5-104 transmission protocol and encrypted using a virtual private network (VPN) connection. The interface is presented in Table I. In the table, input is relative to the house controller, i.e., input means input to the BMS. Of special interest are the first three signals: the first one sends a reading of the current power generation or consumption of the LU to Power Hub, the second method provides a requested 
TABLE I

POWER Hub INTERFACE

\begin{tabular}{l|l}
\hline $\begin{array}{l}\text { Current generation/con- } \\
\text { sumption }\end{array}$ & $\begin{array}{l}\text { Analogue output for the current consump- } \\
\text { tion }\end{array}$ \\
\hline $\begin{array}{l}\text { Set point for generation/ } \\
\text { consumption }\end{array}$ & $\begin{array}{l}\text { Analogue input for the requested consump- } \\
\text { tion }\end{array}$ \\
\hline Current capacity & Analogue output for the current capacity \\
\hline Power Hub enabled & $\begin{array}{l}\text { Digital output for LU owners to turn on/off } \\
\text { Power Hub control }\end{array}$ \\
\hline LU running & Digital output reading LU running state \\
\hline LU error & $\begin{array}{l}\text { Digital output for reading potential LU error } \\
\text { state }\end{array}$ \\
\hline LU start & Digital input for starting LU \\
\hline LU stop & Digital input for stopping LU \\
\hline
\end{tabular}

power set point to the LU, which is the optimal power consumption or generation with respect to the power market. The third method sends an abstract measure of the capacity of the unit back to Power Hub, which is LU specific and depends on the process that the LU is running. Examples of capacity can be the level of fuel in diesel genset, level of water in a reservoir for hydro power or deviation from a reference temperature in a cold storage. Using the measure of capacity Power Hub maintains knowledge of the state of its LUs and how much consumption or generation that can be postponed or accelerated. Constraints on capacity and power consumptionor generation-are defined by LU owners together with Power Hub administrators prior initialization of the LU, and are maintained as static data in Power Hub. Additionally to the methods stated above, there is a digital input in the RTU reading the pulse output from an electricity meter mounted on the site of the LU. This input is for Power Hub to verify consumption or generation.

\section{FlexHouse}

FlexHouse is an intelligent office building located at the DTU Ris $\varnothing$ Campus near Roskilde, Denmark. The building is a part of SYSLAB, a research facility for control in distributed power systems, where it is utilized as a flexible load. It is fitted with a wide range of sensors and actuators, which allow the building to be monitored and controlled from a custom-made BMS. The area of FlexHouse is approximately $120 \mathrm{~m}^{2}$, distributed over seven offices and a large meeting room, together with a small kitchenette and a toilet. The building is free-standing, mounted on concrete slaps, thus leaving a gap between the ground and the underside of the building. The building envelope is made from plywood on the outside and plasterboards on the inside, sandwiching a layer of insulation. Consequently, FlexHouse is a thermally light building, relative to an average Danish building. Likewise, the level of insulation is quite low compared to an average Danish building. Space heating in FlexHouse comes from ten electrical space heaters that are distributed equally inside the building. The rated power of the heaters ranges from 0.975 to $1.250 \mathrm{~kW}$, with a total rated peak power of $9.75 \mathrm{~kW}$. Moreover, there are five heat pumps providing heating during winter and cooling during summer. These have not been utilized in the research presented in this paper.

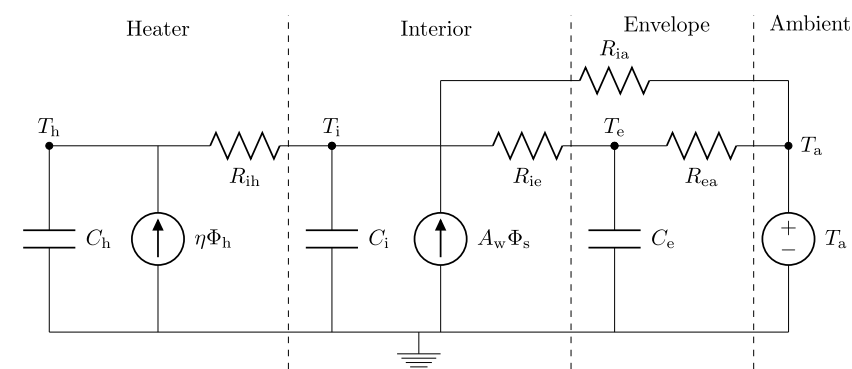

Fig. 1. RC-diagram for prediction model.

\section{Heat Dynamic Model for Prediction of the Heat Load}

Daily, for each LU, Power Hub expects to receive a load or generation forecast for the following day of operation. In this section, we derive a heat dynamic model for prediction of the heat load of FlexHouse. No later than 10 A.M. Power Hub must receive the forecast of the expected heat consumption in FlexHouse for the following day. Hence, the heat load should be predicted from 14 to $38 \mathrm{~h}$ in advance. Naturally, predictions of the heat load up to $38 \mathrm{~h}$ in advance has a high uncertainty attached, especially considering the uncertainty coming from the weather forecast. However, the heat load of a small house connected in the low voltage grid should-ideally—be seen as part of an aggregate system, where the uncertainty of an aggregate forecast decreases as the number of heat loads increases. An exception to this is, naturally, when a weather forecast is wrong the aggregate forecast is also likely to be wrong. This, however, is one of the main reasons why Power Hub has been developed; to handle imbalances during the day. Another example is when a weather front is delayed with respect to a forecast, potentially delaying the power generation from a wind farm. This can be handled by Power Hub, by postponing the heating of households until the weather front has arrived and power generation has reached a predicted level.

A linear time-invariant model of the heat dynamics of FlexHouse has been developed for predictions of the indoor temperature and heat load. This model is currently being used in various applications using FlexHouse as a source for provision of DR, e.g., in EMPC of the heat load using an actual time varying price signal from the Nordic power market [11]. By approximating the temperature to be homogeneous distributed in the indoor air, including the interior mass, the space heaters, and the building envelope, respectively, the model can be formulated as a lumped model. The RC-diagram presented in Fig. 1 illustrates how the heat dynamics of the building are modeled. At the top is noted the three temperature states, i.e., the heaters, interior, and envelope states, each represented by a capacitor in the diagram, together with the ambient environment to the far right. The heaters are seen to receive a heat input $\Phi_{h}$, which is multiplied by the efficiency factor, $\eta$. The heaters are seen to exchange heat with the interior state only, which exchanges heat with the ambient environment directly and through the building envelope. Moreover, the interior state receives heat input from solar irradiance, $\Phi_{s}$, coming through the windows with an effective area $A_{w}$. Finally, the envelope is exchanging heat with both the interior state and the ambient environment. To account for disturbances not encompassed 
TABLE II

MAXIMUM LIKELIHOOD ESTIMATES OF MOdel Parameters in (1)

\begin{tabular}{c|c}
\hline Parameter & Estimate \\
\hline \hline$A_{w}$ & $14.52 \mathrm{~m}^{2}$ \\
\hline$C_{e}$ & $4.17 \mathrm{kWh} /{ }^{\circ} \mathrm{C}$ \\
\hline$C_{h}$ & $0.00227 \mathrm{kWh} /{ }^{\circ} \mathrm{C}$ \\
\hline$C_{i}$ & $2.54 \mathrm{kWh} /{ }^{\circ} \mathrm{C}$ \\
\hline$R_{e a}$ & $3.61{ }^{\circ} \mathrm{C} / \mathrm{kW}$ \\
\hline$R_{i e}$ & $0.84{ }^{\circ} \mathrm{C} / \mathrm{kW}$ \\
\hline$R_{i h}$ & $139.22{ }^{\circ} \mathrm{C} / \mathrm{kW}$ \\
\hline$R_{i a}$ & $36.99{ }^{\circ} \mathrm{C} / \mathrm{kW}$ \\
\hline$\eta$ & $\equiv 1$
\end{tabular}

by the model, e.g., unrecognized or noisy measurement of input, the energy balance equations are formulated as three coupled stochastic differential equations (SDE). From Fig. 1, the energy balance equation can be derived

$$
\begin{aligned}
d T_{i} & =\left(\frac{T_{h}-T_{i}}{R_{i h} C_{i}}+\frac{T_{e}-T_{i}}{R_{i e} C_{i}}+\frac{T_{a}-T_{i}}{R_{i a} C_{i}}+\frac{A_{w} \Phi_{s}}{C_{i}}\right) d t+\sigma_{1} d \omega_{1} \\
d T_{h} & =\left(\frac{T_{i}-T_{h}}{R_{i h} \cdot C_{h}}+\frac{\Phi_{h}}{C_{h}}\right) d t+\sigma_{2} \cdot d \omega_{2} \\
d T_{e} & =\left(\frac{T_{a}-T_{e}}{R_{e a} \cdot C_{e}}+\frac{T_{i}-T_{e}}{R_{i e} \cdot C_{e}}\right) d t+\sigma_{3} \cdot d \omega_{3}
\end{aligned}
$$

where $T_{i}, T_{h}$, and $T_{e}$ are the temperature states for the indoor air, heaters, and building envelope, respectively. $R_{i h}$ is the thermal resistance-also known as the UA-value-between the heaters and indoor air, $R_{i e}$ is the thermal resistance between the indoor air and the house envelope, $R_{e a}$ is the thermal resistance between the envelope and the outdoor environment, and $R_{i a}$ is the heat transfer from the indoor air directly to the outdoor environment. $C_{i}, C_{h}$, and $C_{e}$ are the heat capacities of the interior mass, heater mass, and envelope mass, respectively. The exogenous disturbances to the equations from the ambient environment are the outdoor temperature $T_{a}$ and the solar irradiance, $\Phi_{s} . \Phi_{h}$ is the controllable electric input of the space heaters. The disturbances not encompassed by the model are described by a diffusion process, added to each of the equations, which is driven by the stochastic process $d \omega$ with variance $\sigma^{2}$. Equation 1 can be written in the state space form

$$
d \boldsymbol{T}=\mathbf{A} \boldsymbol{T} d t+\mathbf{B} \boldsymbol{U} d t+\boldsymbol{\sigma} d \boldsymbol{\omega}
$$

where $\boldsymbol{T}=\left[T_{i}, T_{h}, T_{e}\right]^{T}$ is the state vector, $\boldsymbol{U}=\left[T_{a}, \Phi_{s}, \Phi_{h}\right]^{T}$ is the input vector. $\mathbf{A} \in \mathbb{R}^{3 \times 3}$ and $\mathbf{B} \in \mathbb{R}^{3 \times 3}$ are the state and input matrix, respectively. $\sigma \in \mathbb{R}^{3 \times 3}$ is a diagonal matrix containing the variances of the diffusion process $d \omega \in \mathbb{R}^{3 \times 1}$. Assuming $\omega$ is described by a standard Wiener process the parameters in (2) can be estimated using a maximum likelihood estimation method as described in [12]. Based on a five days time series of the input $\boldsymbol{U}$, sampled at a 5-min interval, the maximum likelihood estimates presented in Table II have been found. In the table, the efficiency of the resistance heaters are assumed to be equal to one which is reasonable for resistance heaters; however, if another heating method were used, e.g., using a heat pump, the efficiency could be significant higher.

By integration of (2), using the parameter estimates presented in Table II, a discrete model with 5 min steps has been derived. This model can be used for discrete prediction of the heat load of FlexHouse given an indoor temperature reference and a forecast of solar irradiance and outdoor temperature. For a more detailed description of the heat dynamic model of FlexHouse, readers are referred to [13] and for maximum likelihood estimates in linear state space models in general [12] and [14].

\section{E. Optimization of Power Consumption}

The power consumed by a number of electric space heaters in the building should be controlled as close to the given set point as possible but without compromising the indoor comfort of the residents of the building. Thus, the controller should take into consideration the trade-off between flexibility and comfort, allowing the users of the building to specify the level of comfort. Assuming $n$ individual electric space heaters, each with rated power $P_{j}$, an optimization problem can be formulated as

$$
\min \left|\sum_{j=1}^{n}\left(x_{j} P_{j}\right)-S\right|+\sum_{j=1}^{n} x_{j} P_{j} w\left(T_{j}\right)
$$

where the decision variable $x_{j} \in\{0,1\}$ is the off/on state of heater $j, P_{j}$ is the rated power of heater $j, S$ is the power set point received from Power Hub and $n$ is the total number of heaters in the building. The weight function, $w(\cdot)$, of the temperature in the room with heater $j$, is used to implement a soft constraint on the discomfort felt by the resident, by gradually penalizing temperature deviations from the reference, where $T_{\min }$ and $T_{\max }$ are the minimum and maximum tolerable indoor temperature, respectively. The weight function should penalize heaters being on when the indoor temperature reaches $T_{\max }$. Likewise, should the weight function penalize heaters being off when the indoor temperature reaches $T_{\min }$. In the implementation of flexible demand in FlexHouse, the following weight function has been used:

$$
w\left(T_{j}\right)=\left(\frac{2\left(T_{j}-T_{\mathrm{ref}}\right)}{\Delta T}\right)^{m}
$$

where $m$ is an odd number to create an odd function around the indoor reference temperature, $T_{\text {ref. }} \Delta T=T_{\max }-T_{\min }$ is the width of the comfort band - or temperature band-in which the temperature is allowed to vary. $T_{\text {ref }}$ and $\Delta T$ can be specified by the residents, whereas $m$ is a BMS specific parameter defining the steepness of the weight function on the boundaries. In Fig. 2, some examples of weight functions are presented for a varying $m$.

From the figure it is seen that $w\left(T_{j}\right)<-1$ for $T_{j}<T_{\text {ref }}-$ $\Delta T / 2$, making the last term in (3) to dominate, thus forcing heaters to be turned on. Likewise, $w\left(T_{j}\right)>1$ for $T_{j}>T_{\text {ref }}+$ $\Delta T / 2$ is forcing heaters to be turned off. Due to the time delay in the heat transfer from heaters to the indoor air, the boundaries specified by $\Delta T$, should not be seen as "hard" 


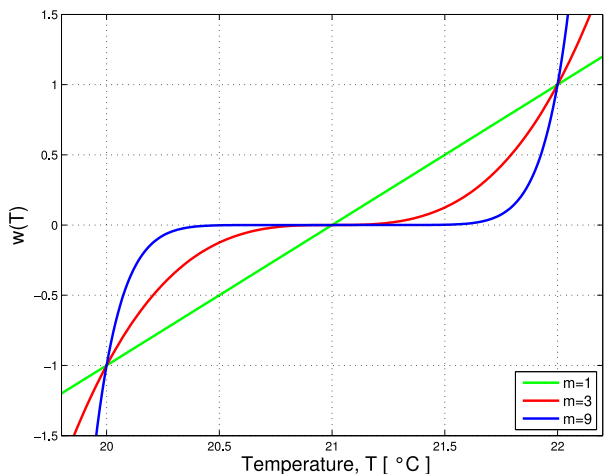

Fig. 2. Weight function with $T_{\text {ref }}=21, \Delta T=2$, and $m=1,3,9$.

boundaries, but a boundary where the heaters are forced to be switched on or off.

The optimization problem formulated in (3) can be split in two, for $\sum_{j=1}^{n}\left(x_{j} P_{j}\right) \geq S$ and $\sum_{j=1}^{n}\left(x_{j} P_{j}\right)<S$, and formulated as two constrained optimization problems. For $\sum_{j=1}^{n}\left(x_{j} P_{j}\right) \geq S$, we find

$$
\begin{gathered}
\min \sum_{j=1}^{n}\left(x_{j} P_{j}\right)-S+\sum_{j=1}^{n} x_{j} P_{j} w\left(T_{j}\right) \\
=\min \sum_{j=1}^{n}\left(w\left(T_{j}\right)+1\right) x_{j} P_{j} \\
\text { s.t. } \sum_{i=1}^{n} x_{j} P_{j} \geq S .
\end{gathered}
$$

Likewise, a constrained optimization problem can be formulated for $\sum_{j=1}^{n}\left(x_{j} P_{j}\right)<S$

$$
\begin{aligned}
& \min \sum_{j=1}^{n}\left(w\left(T_{j}\right)-1\right) x_{j} P_{j} \\
& \text { s.t. } \sum_{i=1}^{n} x_{j} P_{j}<S .
\end{aligned}
$$

These two constrained optimization problems, (5) and (6), can be solved using mixed integer linear programming individually, where the solution with the lowest cost function gives the global solution to (3).

\section{F. Implementation}

For demonstration of flexible demand using FlexHouse, an optimization process for the problem derived in Section II-E was implemented in the BMS, which is controlling the power input to the ten space heaters. Using a bus coupler, the output from the RTU is converted to Modbus over Ethernet, which is read by the BMS. In the optimization process $m \equiv 9$ were used to enforce relative sharp boundaries on the weight function. To ensure a fast response on changes in power set point the optimization problem, derived in (5) and (6), was solved every time changes in set point was detected. Using the GNU Linear Programming Kit, the problem was solved in sub-seconds; consequently, delivering a DR within a few second from when the updated set point was received. In periods with no changes in set point, the problem was solved every fifth minute. Finally, a fallback controller was implemented in case of lost communication with Power Hub or other errors, e.g., set point out of range. This controller emulates a thermostatic controller with the same reference temperature, $T_{\text {ref }}$, as the set point controller and $0.5{ }^{\circ} \mathrm{C}$ hysteresis.

\section{RESULTS}

Several experiments were conducted during the period from January to April 2013 using FlexHouse as a flexible load. The results from three of these experiments are presented in this section. The indoor temperature reference for all experiments were set to $T_{\text {ref }}=21{ }^{\circ} \mathrm{C}$, with $\Delta T=4{ }^{\circ} \mathrm{C}$ for the first experiment and $\Delta T=8$ for the second and third experiment. The comfort band used for control should be consider an approximation to the actual indoor comfort and should merely serve to illustrate the possibilities in demand response in the low voltage grid rather than providing optimal thermal comfort as in large-scale HVAC systems. Daily, a heat load forecast was generated from the discretized state space model presented in Section II-D using 5 min steps.

\section{A. Flexible Consumption Experiment}

The first experiment was conducted to demonstrate that the heat load can be shifted from day to night, where a surplus of electricity is often available and thus less expensive. Daily, a consumption plan was transferred to Power Hub (see Section II-A). The set point given by Power Hub was the reported forecast, at the given time, with a sinusoid added. The amplitude of the sinusoid was set to $1 \mathrm{~kW}$ and the period to one day, with minima at noon and maxima at midnight. By superimposing the sinusoid on the forecast, 1 $\mathrm{kW}$ of heat load was shifted from midday to midnight. The outcome of the experiment can be seen in Fig. 3, where the heat consumption is seen to follow the set point (top) while the indoor temperature is within the temperature band (bottom). The average heat load during the experiment was close to $6 \mathrm{~kW}$ and hence the $1 \mathrm{~kW}$ load shifted from midday to midnight corresponds approximately to $17 \%$ of the average heat load. The first day the indoor temperature is seen to drop to the boundary of the comfort band and that the power consumption is increasing relative to the set point when the boundary is reached. The drop was caused by an inaccurate forecast of the outdoor temperature, where a $2{ }^{\circ} \mathrm{C}$ lower temperature was observed compared to the forecast; thus, consequently estimating the heat load too low for the given day. From the top plot is noted a daily abrupt drop in set point at noon and likewise the power consumption. The drop in set point was caused by a necessary restart in the FlexHouse BMS, an error that was solved for the following experiments. This drop caused the indoor temperature to decline outside the comfort band, but the controller brought the temperature back up, when the controller was restarted. Furthermore, there was an error in the timestamps in the reported load forecast made for January 27 th which resulted in that the set point was not updated after midnight (gray area). The controller is seen to handle the nonupdated set point and is able to 

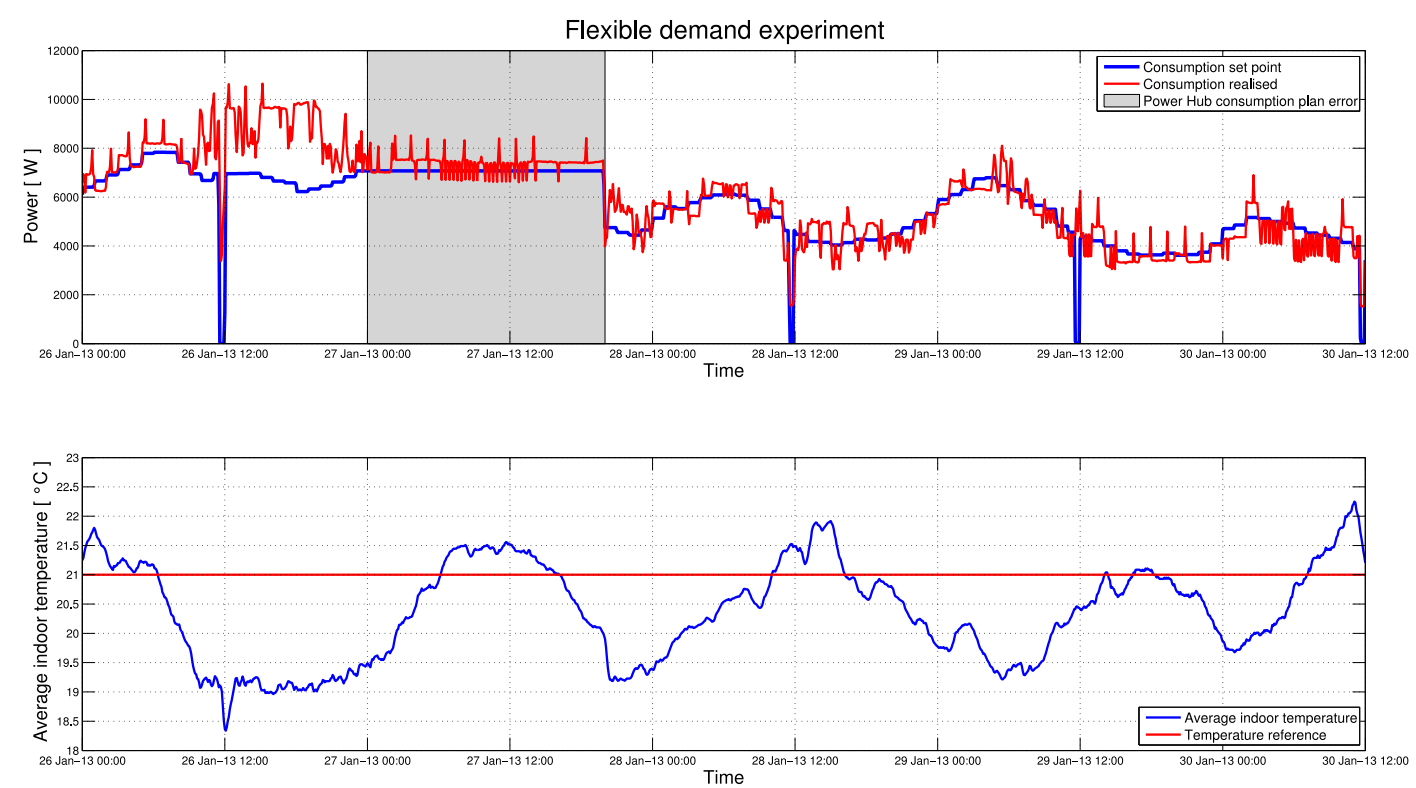

Fig. 3. Flexible load experiment. Top: power set point and actual consumption. Bottom: indoor air temperature.
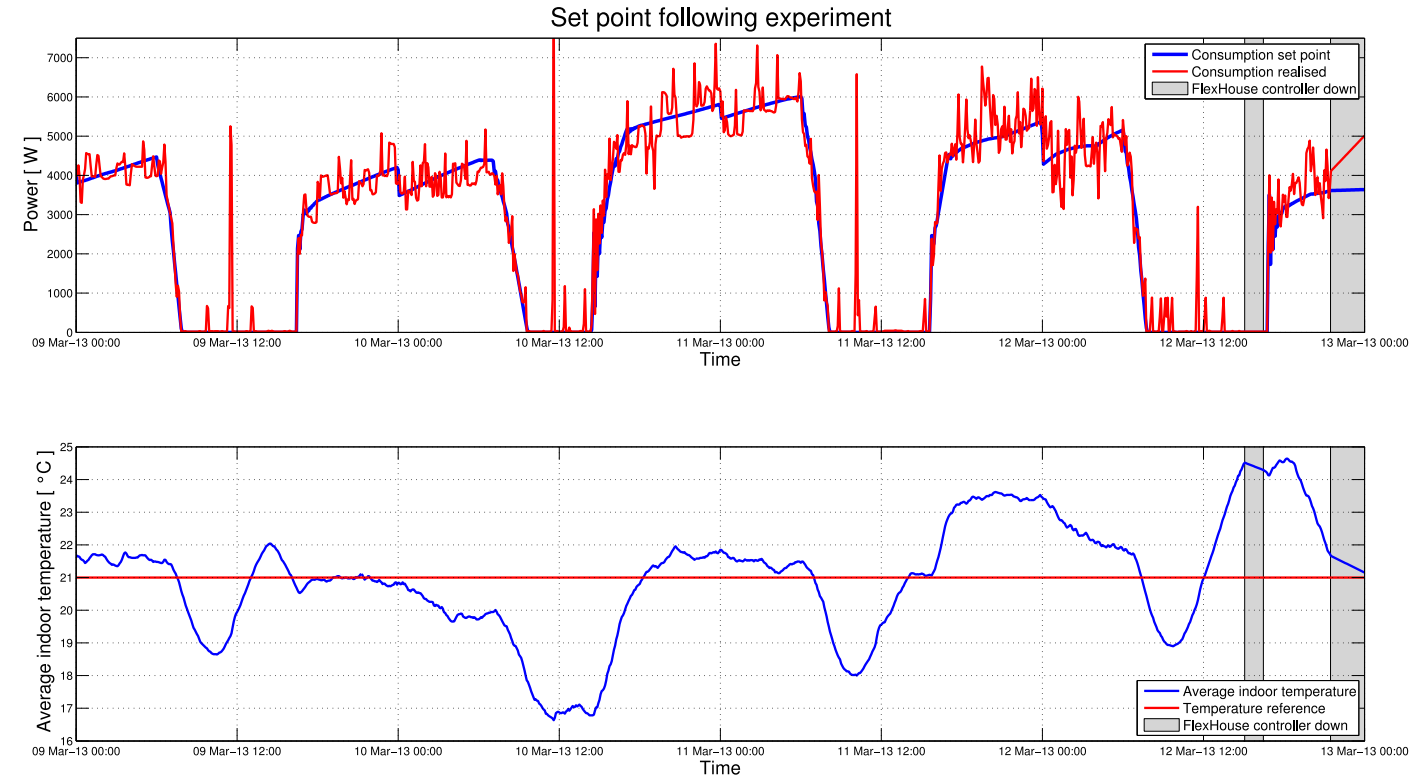

Fig. 4. Set point following consumption. Top: power set point and actual consumption. Bottom: indoor air temperature.

maintain the indoor reference temperature within the comfort band. The error was realized during the 27 th and corrected in the evening. The following three days are seen to proceed without reaching the comfort limits and the controller is actually able to dispatch the requested consumption through the heaters.

\section{B. Set Point Following Experiment}

Subsequently, with the gathered experience from the initial experiments, a new experiment was conducted to see how well the heat load forecast performed by investigating how wide the temperature band had to be to dispatch the predicted power. Thus, the comfort temperature band was widened to $8{ }^{\circ} \mathrm{C}$ and the set point returned by Power Hub was simply given by the load forecast. The outcome of the experiment is presented in Fig. 4, where the actual power consumption is seen to follow the set point quite close considering the discretized power consumption of the ten space heaters, which can only be controlled with a resolution of $0.250 \mathrm{~kW}$. Ideally, if the forecast model described in Section II-D was perfect, the indoor temperature would stay at $21{ }^{\circ} \mathrm{C}$ during the experiment. However, the indoor temperature is seen to vary significantly around the reference temperature, with a maximum of $\pm 4{ }^{\circ} \mathrm{C}$. Especially, around noon, the temperature is seen to decrease periodically and in the afternoon it increases again. The spikes during midday are caused by a restart of the controlling software, where the fallback thermostatic controller takes over. During the restart of the BMS, which takes a few minutes, the thermostatic controller turns on all the heaters in the rooms where the temperature is below $T_{\text {ref }}$ (see Section II-F). 

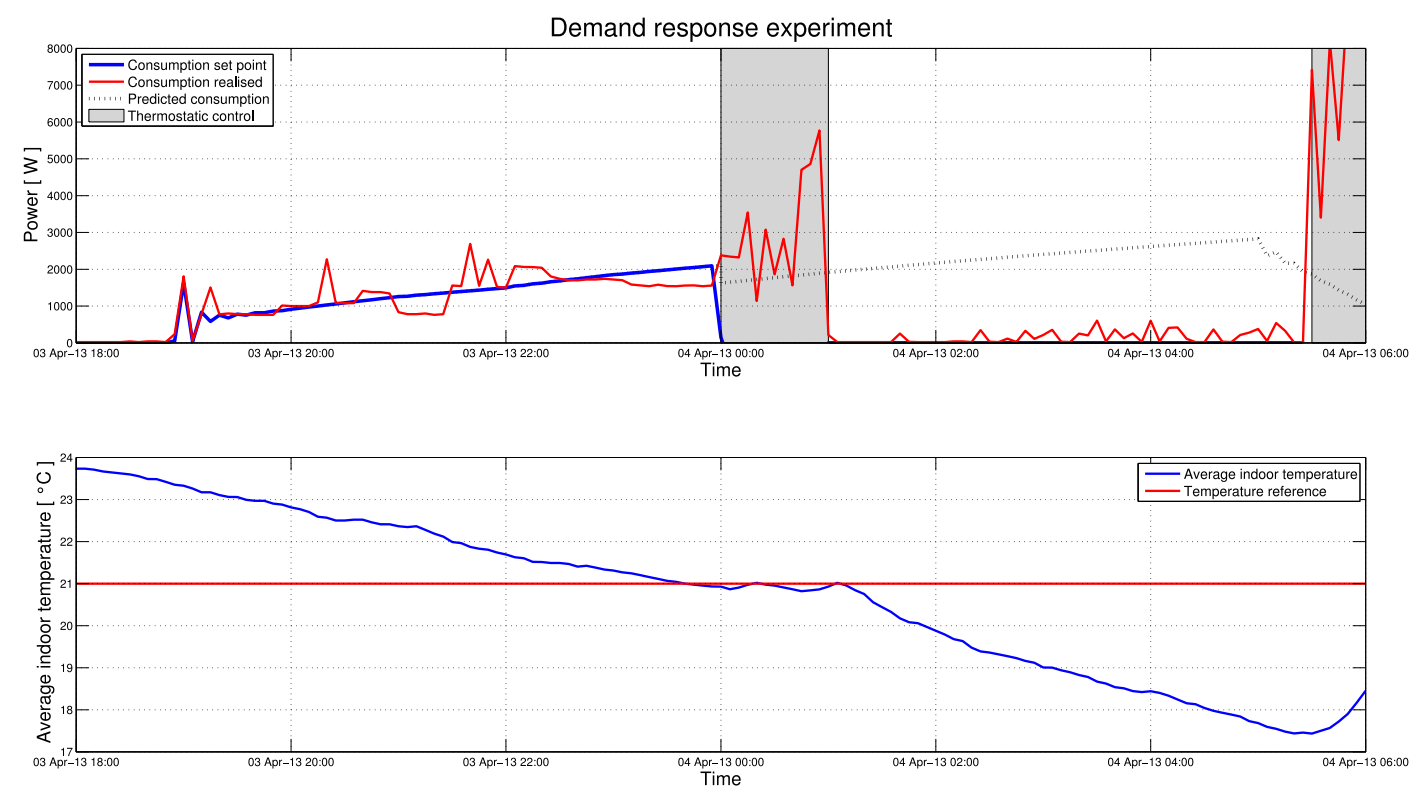

Fig. 5. Demand-response experiment. Top: power set point predicted and actual consumption. Bottom: indoor air temperature.

\section{Demand-Response Experiment}

Fig. 5 shows the outcome of the last experiment, where the impact on the indoor temperature was investigated as a consequence of postponing the heating on request from Power Hub. At the initial day of the experiment, the set point was given by the load forecast as in the previous experiment. At midnight, a negative set point was given, thus activating the fallback thermostatic controller (gray area), which brought the indoor temperature into a known state, i.e., $21^{\circ} \mathrm{C}$ in all rooms. At 1 A.M. the set point was set to zero, thus requesting all heating in the building to be switched off. After a few seconds, the building switched off all heating and within the first hour the indoor temperature is seen to decline approximately $1{ }^{\circ} \mathrm{C}$ after four hours the indoor temperature was declined $3.5^{\circ} \mathrm{C}$. At 5:30 A.M., thermostatic control was reestablished, thus bringing the indoor temperature back to the temperature reference. It is noted that the power consumption is significant higher, relative to the predicted consumption, after heating has been reestablished.

\section{CONCLUSION}

In this paper, a method for providing flexible demand in the low-voltage grid using a direct control scheme has been presented. The method utilizes the infrastructure provided by an operational VPP, by implementing a specified interface. In this way, the BMS of an intelligent office building is able to communicate with the VPP and receive a set point for the requested power usage. It has been demonstrated that the building is able to track a given set point over time, by acceleration and postponement of its power consumption for electric space heating, and in this way adapt to the needs of the power system. Furthermore, with the first experiment it has been demonstrated, that by allowing the indoor temperature to vary within $\pm 2{ }^{\circ} \mathrm{C}$, approximately $17 \%$ of the heat load can be shifted from midday to midnight; a similar result was obtained in [2], where an indirect approach was used to control household appliances.

From the outcome of the 2nd experiment, it is concluded that better models for the prediction of heat loads are needed if the flexibility is to be traded in the day-ahead market. Predictions of the heat load up to $38 \mathrm{~h}$ in advance is simply subject to high uncertainties and likewise is the input data, i.e., weather. However, as stated in Section II-D, the heat load should be seen as an aggregate system, where the uncertainty of the aggregate forecast decreases as the number of LUs increase. Alternatively, due to the small time constants of FlexHouse, the flexible demand could more suitably be traded as balancing power in the intraday market, which has a much shorter trading horizon.

Finally, the last experiment demonstrates that the heat load of a thermally light building can be postponed up to an hour, without having significant impact on the indoor comfort. Considering an aggregate system, under control of a VPP, this means that the heat load of an aggregator can be reduced by $50 \%$ during peak load hours, assuming a $2 \mathrm{~h}$ peak load period. Likewise, in power systems where frequent brownouts or blackouts are experienced, an ability to postpone power consumption for heating-or cooling - could be an important tool to maintain the stability of the power system. Another important thing to notice from this experiment is how fast heating can be reestablished; if no coordinating control is enforced on the reestablishing of heating, congestion problems might arise in the distribution grid. Also, this experiment shows that postponement of heating comes at a price, meaning that lost heating has to be provided later in time.

The results presented in this paper should be seen in the light of that the heat capacity of FlexHouse is quite small; approximately 3-4 kWh $/{ }^{\circ} \mathrm{C}$, Bacher and Madsen [12] compared to approximately $15 \mathrm{kWh} /{ }^{\circ} \mathrm{C}$ for a regular Danish house of similar size, but constructed from bricks and concrete. Also, 
the level of insulation of Danish houses is substantial higher than in FlexHouse, which means that the need for heating is less per area. The average annual power consumption of electrically heated households is around $100 \mathrm{kWh} / \mathrm{m}^{2}$ and the average size of single-family houses is around $140 \mathrm{~m}^{2}$. This means that the annual heat consumption in a single-family household is approximately $14000 \mathrm{kWh} / \mathrm{y}$. When distributed over the seven months heating season in Denmark, this gives an average heat consumption of around $2-3 \mathrm{~kW}$, which is equivalent to what is used for heating FlexHouse. With higher thermal mass and insulation, the time constants of average households are expected to be significantly larger compared to FlexHouse and with the same amount of heating needed, better results with respect to the amount of energy that can be stored in the building structure and variations in indoor temperature, are expected to be found.

In this paper, the parameter used to describe indoor comfort is exclusively given by the indoor temperature. However, indoor comfort is a complex measure and is therefore not given by the temperature alone; generally, indoor comfort comprises parameters for $\mathrm{CO}_{2}$ level, humidity, and thermal radiation from interior walls. Further work should therefore strive to include more optimal comfort indicators like for example predicted mean vote (PMV) and predicted percentage dissatisfied (PPD). Using such indicators, parameters like $\mathrm{CO}_{2}$ level and humidity could be controlled using actuators on windows for control of natural ventilation of the building. Moreover, the discrete state space model, used for prediction of the heat load, should be improved, such that a better forecast of the heat load can be achieved. Instead of formulating the heat dynamic model using SDE existing ISO models, e.g., ISO 13790 [15], could be used to formulate a more adequate model. Finally, future work should include control of the $\mathrm{A} / \mathrm{C}$ from the five heat pumps in FlexHouse, taking into consideration the coefficient of performance, $\eta$, of the heat pumps.

\section{REFERENCES}

[1] A. M. Kosek, G. T. Costanzo, H. W. Bindner, and O. Gehrke, "An overview of demand side management control schemes for buildings in smart grids," in Proc. IEEE Int. Conf. Smart Energy Grid Eng. (SEGE), 2013, pp. 1-9.

[2] D. J. Hammerstrom et al., "Pacific Northwest GridWise testbed demonstration projects-Part I, Olympic Peninsula project," U.S. Dept. Energy, Pacific Northwest Nat. Lab., Richland, WA, USA, Tech. Rep. PNNL17167, 2007.

[3] J. Jorgensen, S. Sorensen, K. Behnke, and P. Eriksen, "EcoGrid EU-A prototype for European Smart Grids," in Proc. IEEE Power Energy Soc. Gen. Meeting, San Diego, CA, USA, 2011, pp. 1-7.

[4] Energinet.dk "Cell controller pilot project," Energinet.dk, Tech. Rep. 8577/12, 2011.

[5] J. Ma, S. Qin, B. Li, and T. Salsbury, "Economic model predictive control for building energy systems," in Proc. IEEE PES Innov. Smart Grid Technol. (ISGT), Hilton Anaheim, CA, USA, 2011, pp. 1-6.
[6] T. Hovgaard, L. Larsen, J. Jørgensen, and S. Boyd, "Nonconvex model predictive control for commercial refrigeration," Int. J. Control, vol. 86, no. 8, pp. 1349-1366, 2013.

[7] F. Oldewurtel, A. Ulbig, A. Parisio, G. Andersson, and M. Morari, "Reducing peak electricity demand in building climate control using real-time pricing and model predictive control," in Proc. 49th IEEE Conf. Decis. Control (CDC), Atlanta, GA, USA, 2010, pp. 1927-1932.

[8] A. Barbato et al., "House energy demand optimization in single and multi-user scenarios," in Proc. IEEE Int. Conf. Smart Grid Commun. (SmartGridComm), Brussels, Belgium, 2011, pp. 345-350.

[9] DONG Energy. (2013, Aug. 15). Power Hub. [Online]. Available: http://www.dongenergy.com/en/innovation/developing/pages/power hub.aspx

[10] TWENTIES, (2013, Jul. 17). Twenties, Transmission System Operation With Large Penetration of Wind and Other Renewable Electricity Sources in Networks By Means of Innovative Tools and Integrated Energy Solutions [Online]. Available: http://www.twenties-project.eu

[11] Y. Zong, D. Kullmann, A. Thavlov, O. Gehrke, and H. W. Bindner, "Application of model predictive control for active load management in a distributed power system with high wind penetration," IEEE Trans. Smart Grid, vol. 3, no. 2, pp. 1055-1062, Jun. 2012.

[12] P. Bacher and H. Madsen, "Identifying suitable models for the heat dynamics of buildings," Energy Buildings, vol. 43, no. 7, pp. 1511-1522, Jul. 2011.

[13] A. Thavlov, "Dynamic optimization of power consumption," Master's dissertation, DTU IMM, Tech. Univ. Denmark, Lyngby, Denmark, 2008.

[14] K. K. Andersen, H. Madsen, and L. H. Hansen, "Modelling the heat dynamics of a building using stochastic differential equations," Energy Buildings, vol. 31, no. 1, pp. 13-24, Jan. 2000.

[15] ISO 13790, "Energy performance of buildings - Calculation of energy use for space heating and cooling," 2008.

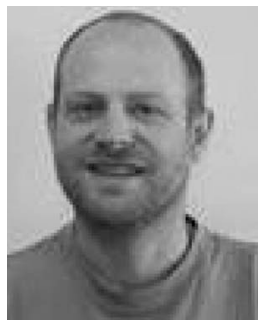

Anders Thavlov (S'12) was born in Copenhagen, Denmark, in 1979. He received the master's degree from the Department of Informatics and Mathematical Modeling, Technical University of Denmark, Kongens Lyngby, Denmark, in 2008, where he is currently pursuing the Ph.D. degree in the Energy System Operation and Management Group from the Department of Electrical Engineering.

His current research interests include stochastic modeling, demand-side management, and power system modeling.

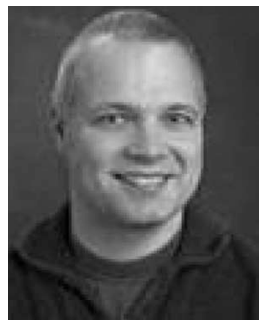

Henrik W. Bindner (M'10) was born in Copenhagen, Denmark, in 1964. He received the M.Sc. degree in electrical engineering from the Technical University of Denmark (DTU), Kongens Lyngby, Denmark, in 1988.

Since 1990, he has been with DTU, where he is currently leading a research group concerned with operation and control of active distribution grids, control of distributed energy resource, and associated information and communications technology (ICT) infrastructures. His current research interests include the fields of integration of renewable energy into the power system, control systems, and ICT infrastructure for management of DERs to enable them to be active participants in the control of the power system. 